\title{
RESEARCH PAPER \\ EFFECTS OF EXTENDED PERIOD OF STORAGE AND STRAIN OF LAYER ON QUALITY OF CHICKEN EGGS
}

\author{
J. K. Hagan' ${ }^{1}$ I. A. Adjei ${ }^{2}$ and A. Baah ${ }^{1}$ \\ ${ }^{I}$ Department of Animal Science, University of Cape Coast, Cape Coast \\ ${ }^{2}$ Department of Mathematics, KNUST, Kumasi. \\ Corresponding author: kofihagan30@gmail.com
}

\begin{abstract}
Poultry farmers in Ghana use different strains of layers for egg production with eggs produced being stored for some time before use. This has necessitated a study to determine the effect of strain of layers and extended storage length on internal and external qualities of chicken eggs. A total of three-hundred (300) eggs from 46-week old layer strains were analysed for egg quality in a 3 X 5 factorial experiment involving three layer strains (Lohmann brown, Lohmann white and Black Bovan) and 5 storage periods of 0, 5, 10, 15 and 20 days. On each day of the analysis, sixty (60) eggs; 20 each from the three strains were randomly sampled and analysed for the internal and external egg characteristics. Results obtained showed a significant difference $(P<0.05)$ among the three layer strains regarding the major egg quality traits like egg weight, albumen weight, haugh unit and yolk weight with the Black Bovan layer strains being superior to the Lohmann strains. It was also observed that the major egg quality traits like egg weight, albumen weight and haugh unit were significantly $(P<0.05)$ affected with increasing storage length. There was also a significant $(P<0.05)$ interaction effects between strain of layer and length of storage of egg on some important egg quality determinants like egg weight, albumen height and haugh unit. This shows that in order not to compromise the quality of eggs, one must consider the strain of layer to use and how long eggs could be stored before use. Irrespective of the strain of layers and storage period, it was realized that egg weight was more closely associated $(P<0.05)$ with albumen height and weight than the other traits.
\end{abstract}

Keywords: Albumen height, egg quality, egg weight, haugh unit, storage length, strain

\section{INTRODUCTION}

Egg quality has been defined by Stadelman and Pratt (1989) as the characteristics of the egg that affect its acceptability to the consumer. Egg quality is the most important price contrib- uting factor in table and hatching eggs. Therefore, the economic success of a laying flock solely depends on the total number of quality eggs produced. If the eggs do not meet the perceived expectations, consumer confidence di- 


\section{Hagan et al.}

minishes. The structural quality of shell eggs is important to the processor because eggs that are structurally sound will arrive to the consumer in the best condition. Furthermore, Jones et al. (2002) in a study on commercial use of eggs found out that, high quality is of importance to egg product manufacturers because it allows for better separation of components without crossover contamination, especially when producing albumen products. The quality of egg and their stability during storage are largely determined by their physical and structural composition.

Egg quality according to Kul and Seker (2004) is measured using the shell, albumen and yolk as indices and may be divided into internal and external; with the production of eggs with good internal and external qualities being critical to the economic viability of the egg industry. According to Scott and Silversides (2000) long storage of eggs has been found to affect the $\mathrm{pH}$ of the albumen of the egg due to loss of carbon dioxide which is an important determinant of egg quality.

Again, the authors observed that extended periods of storage have been responsible for the decrease in the strength of the vitelline membrane. This may allow nutrients in the yolk to become available to any microorganism that are present in the albumen. Haugh unit which is the measure of the albumen quality and measures the freshness of the egg is one of the determinants of egg quality (Keener et al., 2006). Many studies have linked extended storage length with decreased egg quality (Scott and Silversides, 2000; Jones and Musgroove, 2005; Paditey, 2010). While physical factors such as high temperature and duration of storage might affect egg quality, the stain of layers might also have effect on egg quality. In most layer farms in Ghana, table eggs are stored over a long time depending on the availability of buyers and the distance from the farm to the markets. These eggs are normally stored under room temperature (which could be as high as $35^{\circ} \mathrm{C}$ ) because of non-existence or unavailability of refrigeration facilities.
The commonly used layer strains in the country are: Lohmann, ISA Brown, Bovan, Starcross, Hisex, and Hyline. There is, however, paucity of information on the quality of eggs of these different layer strains. The objectives of the research were to determine and compare the quality of eggs produced by some layer strains used in the country and also to find out the effect of extended period of storage on the quality of eggs produced.

\section{METHODOLOGY}

\section{Location of the experiment}

The experiment was carried out at the Teaching and Research Farm of the School of Agriculture, University of Cape Coast. The farm is located at the Eastern part of the University. Eggs were collected from Lohmann Brown (brown feathered and laid brown-shelled eggs), Lohmann Classic (white feathered and laid white-shelled eggs) and Black Bovan (black feathered and laid brown-shelled eggs) which were being kept for a laying trial.

\section{Experimental design and materials used}

A total of three-hundred (300) eggs from 46week old layer strains were analysed for egg quality in a 3 X 5 factorial experiment involving three layer strains ((Lohmann brown, Lohmann white and Black Bovan) and 5 storage periods of $0,5,10,15$ and 20 days. On each day of the analysis, sixty (60) eggs; 20 each from the three strains were randomly sampled and analysed for the internal and external egg characteristics.

\section{Egg quality analysis}

Eggs were evaluated on individual basis for internal and external quality traits. The following constituted external egg characteristics: egg weight $(\mathrm{g})$, egg length and width $(\mathrm{mm})$, shell weight $(\mathrm{g})$ and thickness $(\mathrm{mm})$. The determinants of internal egg quality traits are: albumen weight $(\mathrm{g})$, albumen height $(\mathrm{mm})$, yolk height (mm) and haugh unit (\%). Egg dimensions (length and width) and shell thickness were measured using digital vernier calipers as explained by Al-shami et al. (2011). Eggs were 
weighed to the nearest $0.01 \mathrm{~g}$ using a digital weighing balance. Total egg weight, yolk and eggshell were determined using an electronic balance (precision $0.01 \mathrm{~g}$ ). The shell thickness was determined by first cleaning the shells with tissue paper and air-drying at room temperature for 24 hours. Then, three pieces of shell was taken from the narrow side (sharp region), the middle side (equatorial region), and the broadend side (blunt region) of each egg. This was after the shell membranes had been removed and then the thickness measured by a digital caliper to the nearest of $0.05 \mathrm{~mm}$. The shell thickness ( $\mathrm{mm}$ ) was then calculated as an average of the thicknesses of the three pieces (Ehtesham and Chowdhury, 2002).

For the determination of the internal qualities, individual eggs were broken out and the albumen and yolk height measurements were taken using a tripod micrometer screw gauge (Nonga et al., 2010). The diametres of the yolk and albumen were also measured using a sensitive micrometre to the nearest $0.01 \mathrm{~mm}$. Albumen was carefully separated from the yolks and eggshells before weighing. Albumen weight was retrieved by subtraction (Albumen weight = Total weight - yolk weight - eggshell weight) (Parmar et al., 2006). The weights were then calculated in relation to egg weights and expressed as percentages (Kumari et al., 2008). After the egg had been broken onto a flat plate to determine the internal egg characteristics, a Roche yolk colour fan with values from 1-14 representing pale yellow to deep yellow was used to compare the colour of the yolk. Haugh unit was calculated from the values obtained from albumen height and egg weight by employing the formula as proposed by Haugh (1937):

$\mathrm{HU}=100 \log \left(\mathrm{AH}+7.57-1.7 \mathrm{EW}^{0.37}\right)$

where: $\mathrm{HU}=$ Haugh unit,

$\mathrm{AH}=$ albumen height in $\mathrm{mm}$ and

$\mathrm{EW}=$ egg weight in grams.
The correlation values related to the internal and external egg quality characters irrespective of chicken stains or storage length were determined. The model below was used for the analysis:

$Y_{i j k}=\mu+S_{i}+L_{j}+(S L)_{i j}+E_{i j k}$

Where $\mu$ is the overall mean,

$S_{i}$ is the fixed effect of the $i^{\text {th }}$ strain,

$L_{j}$ is the fixed effect of the $j^{\text {th }}$ storage period,

$(S L)_{i j}$ is the interaction of the $i^{\text {th }}$ strain with the

$j^{\text {th }}$ storage period

$E_{i j k}$ is the random error

\section{Data analysis}

Data for fresh and stored eggs were subjected to two-way analysis of variance with strain and storage length effects using the General Analysis of Variance procedure of GenStat Discovery Edition (Lawes, 2004). Where significant differences were observed treatment means were separated using the least significant difference (lsd) at $5 \%$ level of significance.

\section{RESULTS AND DISCUSSION}

Table 1 shows the effects of storage length and strain of layers on the egg external characteristics. It was observed that Black Bovan layers produced significantly $(\mathrm{P}<0.05)$ heavier eggs as compared to the Lohnman strains, an indication of genetic effect on egg weight. This confirms the observations by Pott et al. (1974), Arafa et al. (1982), Monira et al. (2003) and Alewi et al. (2012) that the weight of eggs was influenced by the type of breed. Egg shell weight and shape index were also significantly influenced by strain of layer with Black Bovan layers laying significantly eggs with superior shell qualities than the Lohmann strains. This also confirms the observation by Singh et al. (2009) that different strains of laying hens vary significantly in egg shell quality. This could be that 
the Black Bovan strains have been selected for large egg size, making it a better choice if large egg size is desired.

Furthermore, the heavier weight of the Black Bovan strains compared to the Lohmann strains (unpublished observation), might be responsible for the bigger eggs laid by the former, as body weight is directly correlated with egg size. The insignificant difference $(\mathrm{P}>0.05)$ in egg weight between the two Lohmann Strains could be as a result of close relationship between the two strains, that is, the two strains might have close ancestry. This is in contrast with observations by Curtis et al. (1986), Washburn (1990) and Singh et al. (2009) that Lohmann brown layers are heavier and lay bigger eggs than their white-feathered counterparts. Again, there were no significant differences $(\mathrm{P}>0.05)$ in egg shell thickness, percent egg shell and egg length, among the three strains of layers, an indication of no genetic effects on these external egg parameters.

There was a significant $(\mathrm{P}<0.05)$ effect of storage length on the external egg quality traits as evidenced by the significant reduction in egg weight, percent shell and shell weight (Table 1) with increased storage length. According to Jones et al. (2002), commercial eggs were graded based on weights into different sizes as "AA" (above 62g), "A" (58g-62g) and grade "B" (52g-57g); with eggs weighing below 52g being commercially unacceptable. From the results obtained in this study, it could be seen that, just five days of storage caused significant $(\mathrm{P}<0.05)$ reduction in egg weight thereby reducing grade "A" eggs (60g) to grade "B" egg $(57.5 \mathrm{~g})$. This implies that the value of eggs, for that matter the market price is likely to reduce as eggs are stored beyond five days under room temperature. The reduction in quality, according to Jones et al. (2002), is due to the rapid loss of moisture from the egg content to the surrounding atmosphere through the egg shell pores. The results obtained in the present study were consistent with observations made by Jones and Musgroove (2005), Samli et al.
(2005), Moula et al. (2009) and Raji et al. (2009) that prolonged storage could lead to a reduction in egg weight.

Results from the present study also showed a relationship between storage length and percent shell thickness and shell weight as evidenced by the significant $(\mathrm{P}<0.05)$ reduction in these parameters due to prolonged storage length. This confirms earlier reports by Scott and Silversides (2000) and Moula et al. (2009) that because the shell is in direct contact with the surrounding atmosphere, drying is considerably fast and the shell becomes drier as storage length increases, thereby making the shell lighter with age. Again, Jones et al. (2002) as the weight of shell is part of the total egg weight, decrease in weight of the egg will reflect in the decrease in the shell weight because moisture is lost from the shell before the effect is transferred to the content.

This present study found some significant $(\mathrm{P}<0.05)$ interaction effects between strain and storage length with respect to egg and shell weight with fresh eggs from Black Bovan being the heaviest (Table 1). This agrees with similar results by Singh et al. (2009) that the strain of layers used for egg production and the length of period of storage of the eggs could affect the weight of the egg and the shell. From Table 2, it was observed that one of the important determinants of egg quality, haugh unit, was influenced by the strain of layer and length of storage (interaction effect), with fresh eggs from Black Bovan being the best and Lohmann strains' eggs stored beyond 10 days being the worst. The results from the present study give an indication of the relevance of the strain of layers used and period of storage of eggs as far as egg external quality is concerned. The significant interaction effect means irrespective of the strain from which the eggs are obtained, if the eggs are stored over a long period (beyond five days), the value would be compromised.

The effect of strain of layers on egg internal qualities have been presented in Table 2 with 


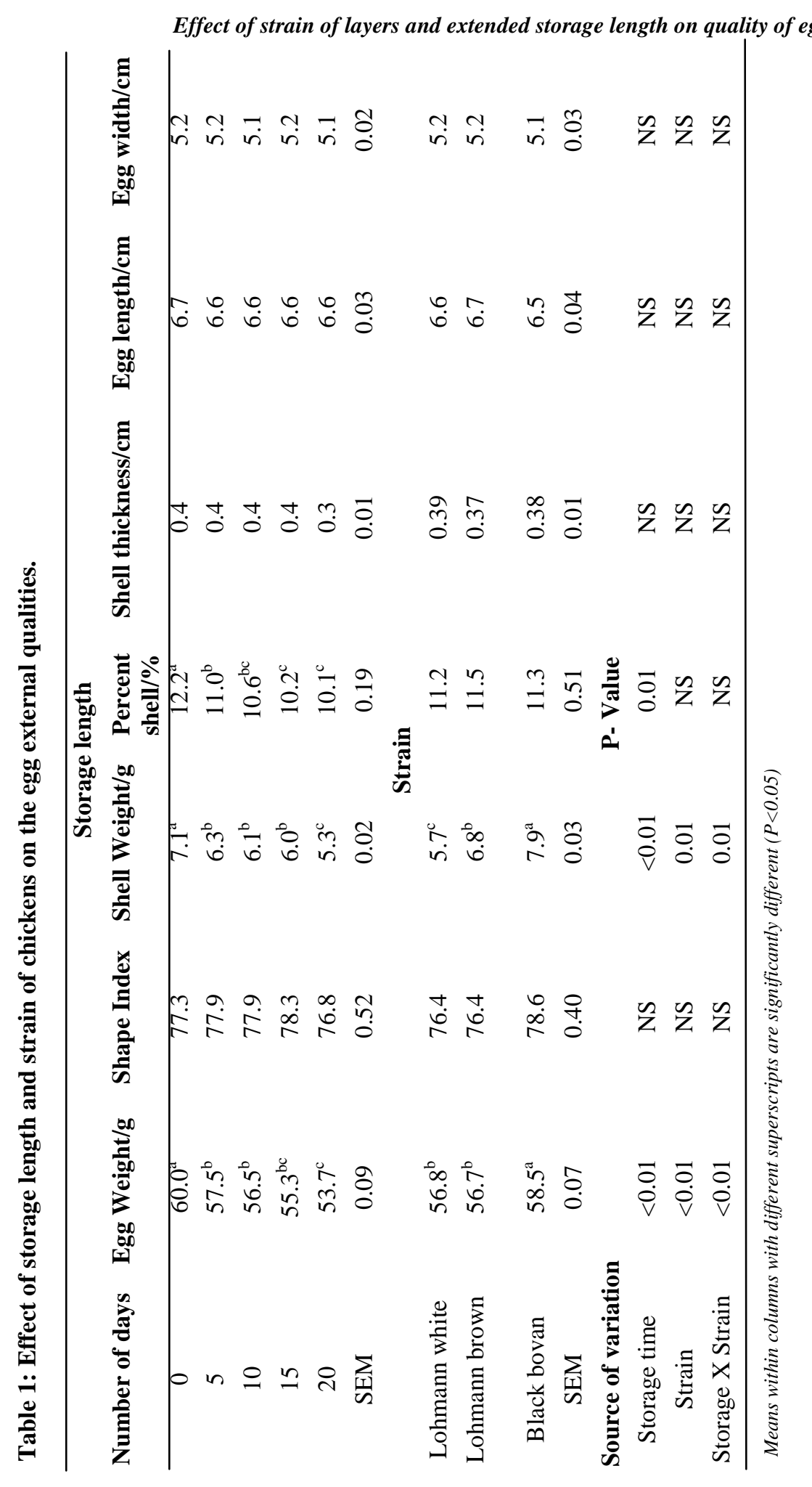

Journal of Science and Technology @ KNUST August 2013 


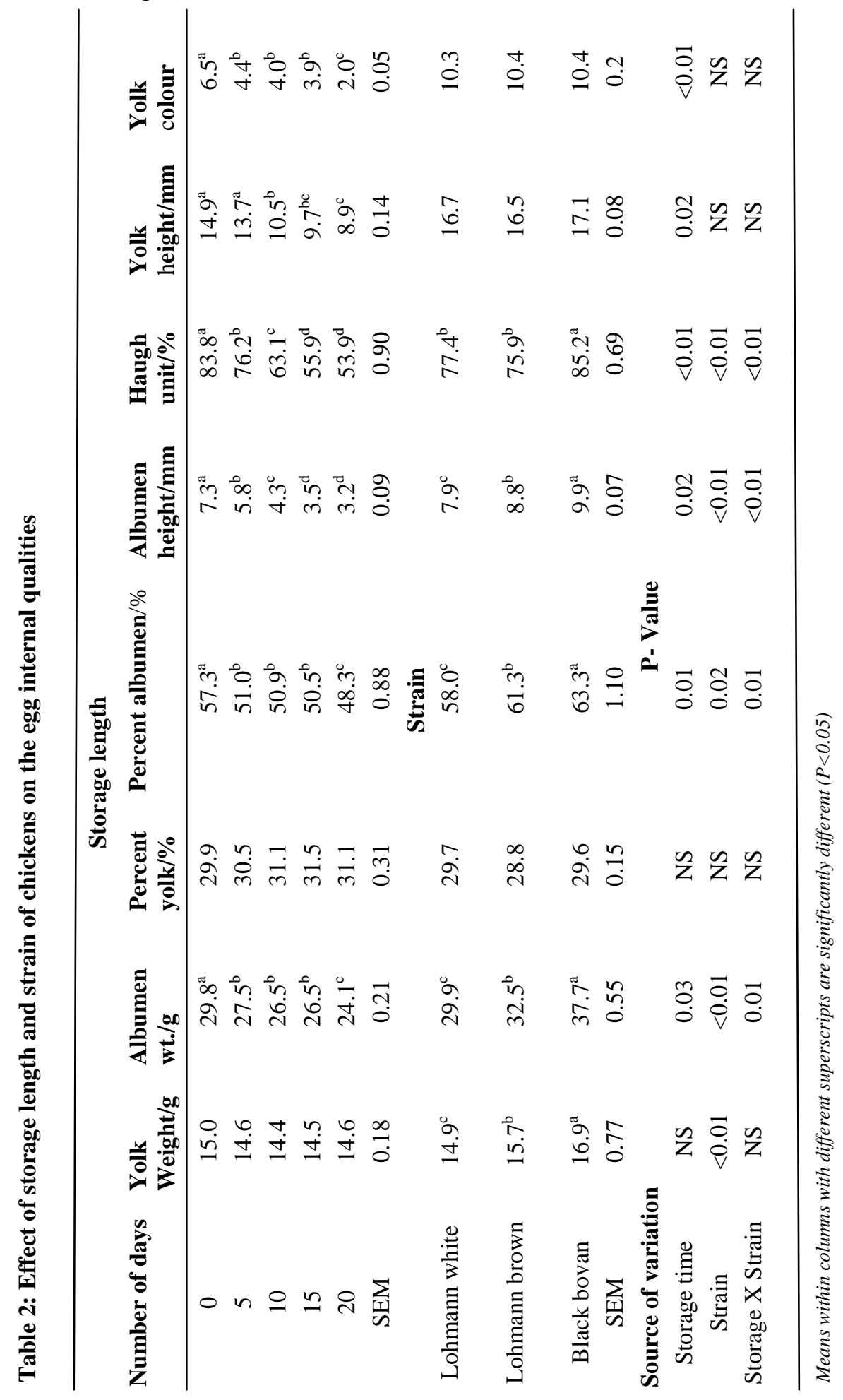

Journal of Science and Technology @ KNUST August 2013 
eggs from Black Bovan having significantly $(\mathrm{P}<0.05)$ heavier yolk weight, albumen weight, better percent albumen, better haugh unit and better albumen height than eggs from the Lohmann strains. Within the Lohmann strains, apart from haugh unit the brown feathered strain was found to be superior to its white feathered counterparts. According to Washburn (1990), there is a correlation between egg weight and albumen weight, meaning that as egg size increases, so does the percent of albumen. Egg freshness is classically measured by its haugh unit (HU) which is the measure of albumen thickness upon breaking of the egg, following a standardized procedure. According to Singh et al. (2009) and Tebesi et al. (2012) lower HU reflects lesser freshness with haugh unit being affected by breed and length of storage of eggs. Results from the present study shows a significant $(\mathrm{P}<0.05)$ storage period and strain effects on egg internal qualities (Table 2). There were significantly dramatic changes in yolk height (from $14.9 \mathrm{~mm}$ to $8.9 \mathrm{~mm}$ ), haugh unit $(83.8$ to $53.9 \%)$, albumen height $(7.3$ to $3.2 \mathrm{~mm}$ ) and percent albumen (53.7 to $48.3 \%$ ) with extended storage length. These results are in conformity with those observed by Scott and Silversides (2000), Samli et al. (2005) and Raji et al. (2009).

According to Ensminger (1992) and Keener et al. (2006) albumen height and haugh unit are among the most important parameters used to describe interior egg quality and subsequently the freshness of the egg. Scott and Silversides (2000) observed that albumen height decreased with storage length due to the fact that moisture and $\mathrm{CO}_{2}$ are lost from egg stored in an open environment and this causes the air cell within the egg to enlarge. Also, the loss in $\mathrm{CO}_{2}$ raises the egg's $\mathrm{pH}$ to become more basic, hence inducing structural changes in the albumen; that is thinning of the albumen which consequently result in a decline in albumen height.

Ensminger (1992) also stated that as egg ages and the albumen thins, an albumen protein called Ovomucin that is essential for embryonic development also begins to denature and resulting in unusual embryonic death during egg incubation. From the results obtained, it could be seen that albumen height of fresh eggs $(7.3 \mathrm{~mm})$ declined to $3.2 \mathrm{~mm}$ after 20 days of storage. These values were above $1.5 \mathrm{~mm}$ for low quality eggs but fell below $11.5 \mathrm{~mm}$ for extremely good and fresh eggs as stated by Scott and Silversides (2000) as standards for eggs to be accepted for industrial use in the confectionery industry for the making of cakes, chocolates, candy among other products. This is an indication of possible rejection of eggs that have been stored over an extended period of time due to a possible loss in value of the egg as a result of the thinning of the albumen.

Haugh unit which is a determinant of egg freshness, was significantly $(\mathrm{P}<0.05)$ affected by storage length; with fresh eggs recording a value of $83.8 \%$ and reducing to $53.9 \%$ after 20 days of storage. It could be seen that after 10 days of storage (Table 2) the freshness of the egg, determined by the haugh unit, has deteriorated below the minimum acceptable value of $70 \%$ for eggs used for industrial purposes (Haugh, 1937). According to Scott and Silversides (2000) haugh unit gives a better indication of egg quality as it combines egg weight and albumen thickness, thereby reflecting the presence and the quality of Ovalbumin, Ovotransferrin, Ovomucoid, Ovomucin, Lysozyme, G2 Globulin, G3 Globulin and Avidin which are all albumen proteins. The decline in haugh unit due to prolonged periods of storage as seen in the present study is in agreement with earlier reports by Silversides and Scott (2001), Keener et al. (2006) and Raji et al. (2009).

Even though yolk colour is affected by diets, there was a significant $(\mathrm{P}<0.05)$ reduction in yolk colour with extended period of storage. The yolk colour observed was generally far below the minimum value of 9.0 as accepted by the International Markets as stated by Jones et al. (2002). There is therefore the need to add green vegetables in the diets of intensively kept 
layers in order to improve the colour of the yolk. The observation made by Jones et al. (2002) that yolk colour reduces from deep gold to pale as storage length increases, was manifested in this study. The reduction in colour implies that the carotenoids and the xanthophylls (precursors of vitamin A), which constitute the pigmentation were undergoing deterioration. According to Benabdeljelil and Merat (1995) the nutritional quality of the egg is directly linked with percent yolk and yolk weight because these parameters are linked to the dry matter content of the egg and essential fatty acids content of the egg. Again, higher yolk percentage, apart from its nutritional benefits in the diets, is also considered positive in the pharmaceutical, confectionary and cosmetic industries. The insignificant differences $(\mathrm{P}>0.05)$ in percent yolk and yolk weight recorded in this present study were in agreement with similar observations by Ahn et al. (1997), Scott and Silversides (2000) and Moula et al. (2009). This could be due to the shielding effect of albumen (albumen bath) resulting in little or no moisture loss from the yolk during storage. Other reasons could be that because the yolk carries the germinal disc (blastoderm) and provides nourishment to the embryo during incubation it needs to be protected; hence nature has made it such that environmental conditions hardly affect the yolk.

Table 3 shows the correlation coefficient between the internal and external egg parameters. It could be seen that egg weight is linked with all the three major components of egg: egg shell, albumen and yolk. Several authors (Fletcher et al., 1983; Washburn, 1990 and Scott and Silversides, 2000) have also reported of positive relationship between egg weight and albumen weight. The positive correlation observed is an indication of a possibility of selecting for albumen weight as an individual trait due to its moderate to high heritability.

\section{CONCLUSION}

The results of this study show that eggs from different strains can differ in characteristics thereby influencing the ultimate use of the eggs. Owing to the importance of yolk and albumen to the egg breaking industry, users of eggs would pay premium price for eggs from

Table 3: The phenotypic correlation between internal and external egg quality traits

\begin{tabular}{lcccccc}
\hline \multirow{2}{*}{$\begin{array}{c}\text { Internal egg quality } \\
\text { traits }\end{array}$} & EW & ST & EL & EWd & EI & SW \\
\hline Yolk weight & 0.06 & 0.04 & 0.14 & 0.26 & -0.02 & 0.35 \\
Yolk height & 0.89 & 0.68 & 0.14 & 0.26 & -0.02 & 0.23 \\
Albumen height & 0.95 & 0.73 & 0.08 & 0.27 & 0.04 & 0.08 \\
Haugh unit & 0.95 & 0.78 & 0.06 & 0.26 & 0.05 & -0.05 \\
Percent Albumen & 0.26 & -0.39 & 0.15 & 0.25 & 0.02 & -0.17 \\
Albumen weight & 0.94 & 0.04 & 0.70 & 0.77 & -0.18 & 0.45 \\
Percent Yolk & -0.21 & 0.22 & -0.21 & -0.15 & 0.02 & -0.06 \\
\hline
\end{tabular}

All correlation coefficient are significant at $P<0.05$

EW: egg weight; ST: shell thickness; EL: egg length; EWd: egg width; EI: egg index; SW: shell weight 
Black Bovan strains because of their superior egg weight, yolk weight and haugh unit. It was also observed that the major egg quality parameters like egg weight, albumen weight and haugh unit decreased with increasing storage length, hence the need to ensure that eggs are properly preserved if they are going to be stored for longer periods. Otherwise eggs should not be stored at room temperature for more than one week. Again, due to the differences in egg quality characteristics among the various layer strains in the country, it would be worthwhile to study the protein, lipid and the mineral contents (quantitatively and qualitatively) of eggs from the various layer strains used in the country. Furthermore, the significant interaction effects observed in some of the egg quality characteristics are indications of the need to consider the strain of layer and how long the eggs can be stored so as not to compromise the quality.

\section{REFERENECS}

Ahn, D. U., Kim, S. M., Shu, H. (1997). Effect of egg size and strain and age of hens on the solids content of chicken eggs. Poultry. Science, 76:914-919.

Alewi, M, Melesse, A. and Teklegiorgis, Y. (2012). Crossbreeding effect on egg quality traits of local chickens and their F1 crosses with Rhode Island Red and Fayoumi chicken breeds under farmers' management conditions. Journal of Animal Science Advances, 2 (8): 697-705.

Al-shami, M. A, Salih, M. E. and Abbas, T. E. (2011). Effects of dietary inclusion of alfafa leaf meal and Xylan enzyme on laying hens' performance and egg quality. Research Opinions in Animal and Veterinary Sciences, 2 (1): 14-18.

Arafa, A. S., Harms, R. H., Miles, R. D., Christmas, R. B. and Choi, J. H. (1982). Quality characteristics of eggs from different strains of hens as related to time of oviposition. Poultry Science, 61: 842-47.
Benabdeljelil, K. and Merat, P. (1995). Comparaison de types génétiques de poules pour une production d'oeufs locale: F (Fayoumi X leghorn) et croisement 1 terminal ISA au Maroc. Annals of Zoo technology, 44: 313318. (Abstract).

Curtis, P. A., Gardner, F. A. and Mellor, D. B (1986). A comparison of selected quality and compositional characteristics of brown and white shell eggs. III. Composition and nutritional characteristics. Poultry Science, 65:501-507.

Ensminger, E. M. (1992). Poultry Science (Animal Agric Series), $3^{\text {rd }}$ Edition. Interstate Publishers Inc. Luinois, U.S.A., Pp 94, 172.

Ehtesham, A, Chowdhury, S.D. (2002). Responses of laying hens to diets formulated by using different feeding standards. Pakistani Journal of Nutrition, 1: 127-131.

Fletcher, D. L., Britton, W. M., Pesti, G. M. and Rahn, A. P. (1983). The Relationship of layer Flock Age and Egg Weight on Egg component Yields and solids content. Poultry Science, 62: 1800-1805.

Haugh, R. R. (1937). The Haugh Unit for measuring egg quality. U.S. Egg Poult. Magazine 43:552-555.

Jones D. R. and Musgrove, M. T. (2005). Effects of Extended Storage on Egg Quality Factors. Poultry Science. 84: 1774-1777.

Jones, D. R, Tharrington, J. B, Curtis, P. A, Anderson, K. E, Deener, K. M. and Jones, F. T.] (2002). Effect of cryogenic cooling of shell eggs on egg quality. Poultry Science. 81: 727- 733 .

Keener, K. M, McAvoy, K. C, Foegeding, J. B, Curtis, P. A, Anderson, K. E. and Osborne, J. A. (2006). Effect of testing temperature on internal egg quality measurements. Poultry Science, 85: 550-555. 
Kul, S. and Seker. I. (2004). Phenotypic correlations between some external and internal egg quality traits in the Japanese quail Cortunix cortunix japonica). International Journal of Poultry Science, 3(6): 400-405.

Kumari, B. P, Gupta, B. R, Prakash, M. G. and Reddy, A. R. (2008). A study of egg quality traits in Japanese quails. Tamilnadu Journal of Veterinary and Animal Science, 4 (6): 227 231.

Lawes (2004). Genstat 4.2 Reference Manual. Oxford University, U.K.

Monira, K. N, Salahuddin, M. and Miah, G. (2003). Effect of breed and holding period on egg quality characteristics of chicken. International Journal Poultry Science, 2:261263.

Moula, N, Antoine-Moussiaux, F, Famir, F. and Leroy, P. (2009). Comparison of egg composition and conservation ability in two Belgian local breeds and one commercial strain. International Journal of Poultry Science, 8 (8):768-774.

Nonga, H. E, Kajuna, F. F, Ngowi, H. A. and Karimuribo, E. D. (2010). Physical egg quality characteristics of free-range local chickens in Morogoro municipality in Tanzania. Livestock Research for Rural Development, 22 (12). Retrieved on the $30^{\text {th }}$ of September, 2012 from http://www.lrrd.org/lrrd22/12/ nong22218.htm.

Paditey S, (2010). The effect of storage length on internal and external characteristics of chicken eggs. (Unpublished BSc. dissertation, School of Agriculture. University of Cape Coast).

Pandey, N. K, Mahapatra, C. M, Verma, S. S. and Johari, D. C. (1986). Effect of strain on physical egg quality characteristics in white leghorn chickens. Indian Journal of Poultry Science, 21: 304-307.
Parmar, S. N. S, Thakur, M. S, Tomar, S. S, Pillai, P. V. A. (2006). Evaluation of egg quality traits in indigenous Kadaknath breed of poultry. Livestock Research for Rural Development, 18, Art. \#132. http:// www.lrrd.org/lrrd18/9/parm18132.htm

Potts, P. L, Washburn, K. W. and Hale, K. K. (1974). Shell evaluation of white and brown egg strains by deformation, breaking strengths, shell thickness and specific gravity. Poultry Science, 53:2167-2174.

Raji, A. O, Ayilu, J, Igwebuike, U. and Chiroma, S. (2009). Effect of storage methods and time on egg quality traits of laying hens in a hot dry climate. Journal of Agriculture and Biological Sciences, 4 (4): 1-7.

Samli, H. E, Agma, A. and Senkoylu. N. (2005). Effect of storage time and temperature on egg quality in old laying hens. Journal of Applied Poultry Research, 14: 548553.

Scott, T. A. and Silversides, F. G. (2000). The effect of storage and strain of hen on egg quality. Poultry Science, 79: 1725-1729.

Silversides, F.G. and Scott, T. A. (2001). Effect of storage and layer age on quality of eggs from two lines of hens. Poultry Science, 80: 1240-1245.

Singh, R, Cheng, K. M. and Silversides, F. G. (2009). Production performance and egg quality of four strains of laying hens kept in conventional cages and floor pens. Poultry Science, 88: 256-264

Stadelman, W. J. and Pratt, D. E. (1989). Factors influencing composition of the hen's egg. World's Poultry Science Journal, 45: 247-266.

Tebesi, T, Madibela, O. R. and Moreki, J. C. (2012). Effects of storage time on internal and external characteristics of guinea fowl 
Effect of strain of layers and extended storage length on quality of eggs... $\quad 11$

(Numidea meleagris) eggs. Journal of Animal Science Advances, 2 (6): 534-542.

Washburn, K.W. (1990). Genetic variation in egg composition. In: Poultry Breeding and Genetics pp: 781-804. Crawford R.D. (Ed.), Elsevier Science Publisher, B V, Amsterdam, The Netherlands. 